Article

\title{
Development and Evaluation of a Screening Tool to Aid the Diagnosis of Cluster Headache
}

\author{
Alina Buture ${ }^{1, *}$, Jason W Boland ${ }^{1}\left(\mathbb{O}\right.$, Lisa Dikomitis ${ }^{2,3} \odot$, Chao Huang ${ }^{1}$ and Fayyaz Ahmed ${ }^{1,4}$ \\ 1 Hull York Medical School, University of Hull, Hull HU6 7RX, UK; jason.boland@hyms.ac.uk (J.W.B.); \\ chao.huang@hyms.ac.uk (C.H.); fayyaz.ahmed@hey.nhs.uk (F.A.) \\ 2 School of Medicine, Keele University, Newcastle-under-Lyme ST5 5BG, UK; 1.a.dikomitis@keele.ac.uk \\ 3 School of Primary, Community and Social Care, Keele University, Newcastle-under-Lyme ST5 5BG, UK \\ 4 Department of Neurology, Hull University Teaching Hospitals NHS Trust, Hull HU3 2JZ, UK \\ * Correspondence: hyab20@hyms.ac.uk
}

Received: 22 December 2019; Accepted: 30 January 2020; Published: 1 February 2020

check for

\begin{abstract}
Cluster headache $(\mathrm{CH})$, a severe primary headache, is often misdiagnosed and mismanaged. The aim of this study was to develop and evaluate a screening tool to aid the diagnosis of $\mathrm{CH}$. We developed a novel 12-item screening tool. This was comprised of four components: (1) images depicting headache pain; (2) pain descriptors; (3) key questions that could differentiate between $\mathrm{CH}$ and migraine; and (4) a visual analogue pain scale. The total possible questionnaire score ranged from 3-32. Patients with $\mathrm{CH}$ and migraines (control group) were recruited prospectively from a headache centre in the North of England, UK. Two-hundred and ninety-six patients were included in the study: $81 \mathrm{CH}$ patients, 36 of which suffer with episodic $\mathrm{CH}$ and 45 with chronic $\mathrm{CH} ; 215$ migraine patients, 92 of which suffer with episodic migraine and 123 with chronic migraine. The mean questionnaire score was higher in $\mathrm{CH}$ patients versus migraine patients (28.4 versus 19.5). At a cut-off score of $>25$ out of 32, the screening tool had a sensitivity of $86.4 \%$ and a specificity of $92.0 \%$ in differentiating between $\mathrm{CH}$ and migraine. The screening tool could be a useful instrument to aid the diagnosis of a $\mathrm{CH}$. The images depicting headache pain do not clearly discriminate between $\mathrm{CH}$ and migraine.
\end{abstract}

Keywords: migraine; images; drawings; questionnaire; sensitivity; specificity; survey; intervention development

\section{Introduction}

A cluster headache $(\mathrm{CH})$ is a severe primary headache with a prevalence of approximately $0.1 \%$ [1]. $\mathrm{CH}$ patients incur a high healthcare cost, estimated in the USA as greater than $\$ 2.8$ billion/year [2]. $\mathrm{CH}$ is characterised by trigeminal distribution of pain, cranial autonomic symptoms and circadian and circannual periodicity [3]. Research indicates that the most common misdiagnosis of $\mathrm{CH}$ is migraine [4-8]. Although $\mathrm{CH}$ has very distinct clinical features, patients often face delay in diagnosis, misdiagnosis, and mismanagement [6,8-11]. It is important that $\mathrm{CH}$ is diagnosed early as effective therapies exist and should be recommended [12]. Misdiagnosis could be avoided if healthcare professionals (such as primary care practitioners, clinicians in secondary and emergency care) are aware of the striking differences between the clinical presentation of $\mathrm{CH}$ and that of migraine. Despite the significant disability and impact on quality of life associated with $\mathrm{CH}$, patients are often in a diagnostic limbo for many years, living with debilitating, severely painful attacks, before a correct diagnosis is made [13]. Misdiagnosis of $\mathrm{CH}$ has a significant impact on patients' daily life, employment, and mental health [14]. Sick leave is high among $\mathrm{CH}$ patients [15]. A correct and timely diagnosis will improve the quality of life, will avoid unnecessary consultations and referrals, and, as a consequence, will reduce the financial and human health resource burden on the healthcare system [13]. Even though 
the diagnostic delays of $\mathrm{CH}$ have decreased over the past decades [16], the timeframe between the onset of the disease and first consultation at a headache centre is still high [9].

Despite significant advances in our understanding of $\mathrm{CH}$ pathophysiology [17-19] and treatment $[20,21]$, the way $\mathrm{CH}$ is diagnosed remains unchanged [3]. To date, since there are no available biological markers to diagnose $\mathrm{CH}$ [3], the diagnosis is entirely based on the clinical history. The lack of knowledge of $\mathrm{CH}^{\prime}$ s clinical characteristics could lead to incomplete history taking and the misdiagnosis of $\mathrm{CH}$. There is a need for a screening tool to aid healthcare professionals to recognise $\mathrm{CH}$. A pilot study by our research team, for which we developed a screening tool with six images depicting headache pain, demonstrated the potential of using visual aids to detect headache severity [22]. Here, we report the results of our large study in which we tested a screening tool for $\mathrm{CH}$.

The aim of this study was to determine the overall performance of a screening tool and the performance of each item in the tool in differentiating between $\mathrm{CH}$ and migraine. We also aimed to determine the performance of images depicting headache pain in discriminating between $\mathrm{CH}$ and migraine.

\section{Materials and Methods}

\subsection{Study Design}

This is a prospective case-control study, evaluating a newly developed 12-item self-administered questionnaire. The study included patients with $\mathrm{CH}$ (the study group) and a group of patients with migraines (control group).

\subsection{Study Population}

All patients were recruited prospectively from a headache centre in the north of England, UK, between October 2017 and March 2019. Patients older than 18 who received a prior diagnosis of $\mathrm{CH}$ or migraine based on the ICHD-3b criteria [23] were invited to participate by A.B. and F.A. Patients with a dual diagnosis of $\mathrm{CH}$ and migraine were excluded from the study.

\subsection{Ethics}

This study has received ethical approvals from the local University Research Ethics Committee (reference no: 1613/27.09.2016) and from the Health and Social Care Research Ethics Committee (HSC REC) (reference no: 16/NI/0269). All patients provided written informed consent to participate. The patients completed the questionnaire un-aided.

\subsection{Screening Tool Development}

The screening tool comprised of four main components: (1) screening tool with six images depicting headache pain (Figure 1) [22]; (2) verbal description of pain; (3) key questions that could differentiate between $\mathrm{CH}$ and migraine; and (4) a visual analogue scale. The images used in the first component were inspired on real life pictures and artistic renditions of headache available online [24-27]. Image ' $a$ ' was inspired on a piece of artwork by Agnes-Cecile for Arte Cluster [22,24,25], and Image ' $\mathrm{e}$ ' was inspired on art created by Faderhead for Deviant Art (Figure 1) [27]. The methodology on how we developed this screening tool with six images depicting headache pain severity has been published [22]. Healthy participants rated image ' $d$ ' and image ' $e$ ' as excruciating, image ' $b$ ' as severe, image ' $c$ ' as severe/moderate, and image ' $f$ ' as depicting mild pain [22]. The International Classification of Headache Disorders-3b (ICHD-3b) [23] criteria and the patients' description of pain in the Cluster Headache: Impact and Perception Study (CHIPS) [28] were used to determine the verbal description of pain, which included categories such as the intensity of the pain (mild, moderate, severe, very severe, excruciating), the nature of the pain (pressure, throbbing, stabbing, burning), and a description of the pain (red hot poker in the eye, pounding heart in the head) [29]. The key questions were provided by 10 UK-based headache specialists, members of the British Association for the Study of Headache 
(BASH) $[30,31]$. The headache experts were invited to participate via email. They were asked to provide questions that they thought were able to differentiate between $\mathrm{CH}$ and migraine during a clinical consultation. The most asked questions provided by the headache specialists were included in the screening tool.

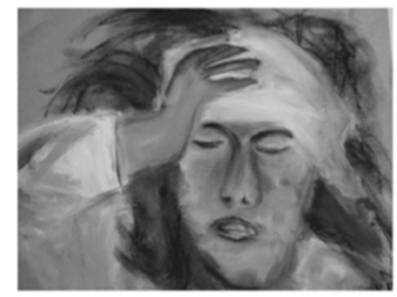

Image a

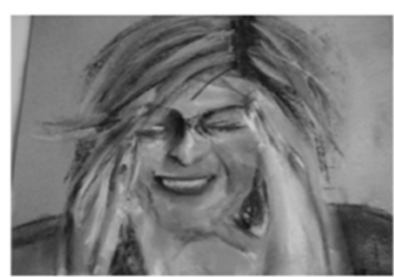

Image c

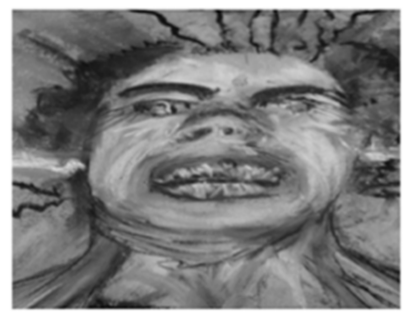

Image e

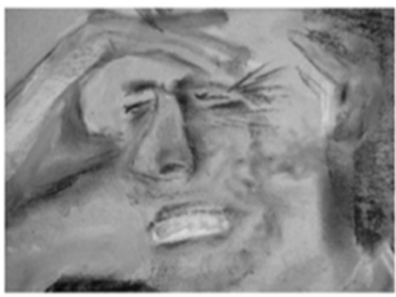

Image b

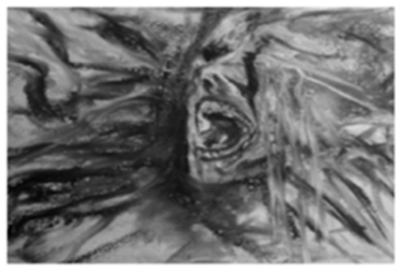

Image d

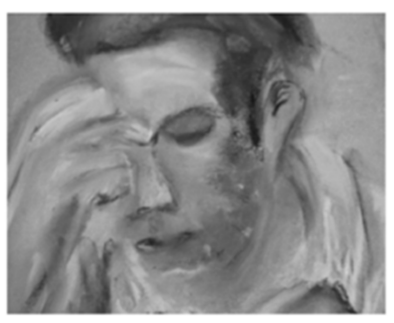

Image $f$

Figure 1. Images depicting different pain severities.

The questionnaire was pilot tested on patients with $\mathrm{CH}$ and migraine. Concerns were raised by the patients with migraine as to whether they should report their mild headaches or migraine attacks. To avoid confusion, the questionnaire was customised based on diagnosis (i.e., 'Please choose one image that best illustrates your cluster headache attacks?' versus 'Please choose one image that best illustrates your migraines?') (see Supplementary File).

\subsection{Statistical Methodology}

Analysis

The dataset was analysed via descriptive analysis [32]. The frequency distribution (counts and percentages) of the categories within each of the 12 variables used to evaluate the performance of the screening tool were summarised for each group of patients. The test scores were coded numerically as defined in Table 1. Higher scores were given for test items characteristic for $\mathrm{CH}$. A dichotomous scale (no $=0$; yes $=1$ ) was used for the test items with binary responses (restlessness, excruciating agony, headache at specific times, strictly unilateral pain, ipsilateral cranial autonomic symptoms). Test items for the severity of pain were coded as follows: image preference ( $f=1$ (least severe); $a=2 ; c=3 ; b=4$; $\mathrm{e}=5 ; \mathrm{d}=6$ (most severe)) [22], the pain scale (scores from zero to ten), and the intensity of pain (mild $=1$; moderate $=2$; severe $=3$; very severe $=4$; excruciating $=5$ ). The description of pain as a 'red hot poker in the eye', which is usually attributed to $\mathrm{CH}$ [29], was coded with 1, whilst a 'pounding heart in the head/other' was coded with 0 . A 'stabbing/burning' pain that describes $\mathrm{CH}$ [33] was coded with 3 , while 'pressure' was coded with 2 , and 'throbbing/other' with 1 . The attack duration of $\leq 3 \mathrm{~h}$, which 
characterises $\mathrm{CH}$, was coded with 1 , whilst the attack duration $>3 \mathrm{~h}$ was coded with 0 . A total score was determined by adding up the scores for the 12 items in the screening tool [34]. The total score was analysed to evaluate the overall performance of the screening tool. Table 2 shows that the minimum possible total score $=3$, and the maximum possible total score $=32$. The descriptive statistics (mean \pm $95 \% \mathrm{CI}$ ) of the total score were compared between each group of patients.

Table 1. Variables measured with the 12-item screening tool.

\begin{tabular}{|c|c|c|}
\hline Question & Variable & Coded Test Scores \\
\hline $\begin{array}{l}\text { 1. Please choose one image that best } \\
\text { illustrates the most severe headache you } \\
\text { have experienced }\end{array}$ & Image preference & $\begin{array}{l}\mathrm{f}=1 \text { (least severe); } \mathrm{a}=2 ; \mathrm{c}=3 ; \mathrm{b}=4 \\
\mathrm{e}=5 ; \mathrm{d}=6 \text { (most severe) }\end{array}$ \\
\hline $\begin{array}{l}\text { 2. Please mark with an } X \text { the intensity of } \\
\text { your pain on the scale below }\end{array}$ & Pain scale & $\begin{array}{l}\text { Scores from zero to ten } \\
(0=\text { No pain; } 5=\text { Moderate pain; } \\
10=\text { Worst possible pain })\end{array}$ \\
\hline $\begin{array}{l}\text { 3. Please choose only one option from } \\
\text { the following list that describes } \\
\text { your headaches }\end{array}$ & Intensity & $\begin{array}{l}\text { Mild }=1 ; \text { Moderate }=2 ; \text { Severe }=3 ; \\
\text { Very Severe }=4 ; \text { Excruciating }=5\end{array}$ \\
\hline $\begin{array}{l}\text { 4. Please choose only one option from } \\
\text { the following list that describes } \\
\text { your headaches }\end{array}$ & Nature of pain & $\begin{array}{l}\text { Throbbing/Other }=1 ; \text { Pressure }=2 ; \\
\text { Stabbing/Burning }=3\end{array}$ \\
\hline $\begin{array}{l}\text { 5. Please choose only one option from } \\
\text { the following list that describes } \\
\text { your headaches }\end{array}$ & Description of pain & $\begin{array}{l}\text { Red hot poker in the eye }=1 \text {; } \\
\text { Pounding heart in the head/Other }=0\end{array}$ \\
\hline $\begin{array}{l}\text { 6. Do you feel restless during the } \\
\text { headache attack? }\end{array}$ & Restlessness & No $=0 ;$ Yes $=1$ \\
\hline 7. Is the pain 'excruciating agony'? & Excruciating agony & $\mathrm{No}=0 ; \mathrm{Yes}=1$ \\
\hline $\begin{array}{l}\text { 8. Does the pain wake you up from } \\
\text { sleep the same time each night/ or attack } \\
\text { comes at a specific time of the day? }\end{array}$ & Headache at specific times & $\mathrm{No}=0 ; \mathrm{Yes}=1$ \\
\hline 9. Is the pain strictly on one side? & Strictly unilateral pain & $\mathrm{No}=0 ; \mathrm{Yes}=1$ \\
\hline $\begin{array}{l}\text { 10. Ipsilateral cranial autonomic } \\
\text { symptoms (e.g., red watery eyes } \\
\text { and/or runny nose?) }\end{array}$ & $\begin{array}{l}\text { Ipsilateral cranial } \\
\text { autonomic symptoms }\end{array}$ & No $=0 ;$ Yes $=1$ \\
\hline $\begin{array}{l}\text { 11. How long does the most severe pain } \\
\text { last for with medication? }\end{array}$ & Treated attack duration & $>3 \mathrm{~h}=0 ; \leq 3 \mathrm{~h}=1$ \\
\hline $\begin{array}{l}\text { 12. How long does the most severe pain } \\
\text { last for without medication? }\end{array}$ & Untreated attack duration & $>3 \mathrm{~h}=0 ; \leq 3 \mathrm{~h}=1$ \\
\hline
\end{tabular}

Table 2. Computation of the total score.

\begin{tabular}{llll}
\hline Variable & & Minimum & Maximum \\
\hline 1 & Image preference & 1 & 6 \\
2 & Pain scale & 0 & 10 \\
3 & Intensity & 1 & 5 \\
4 & Nature of pain & 1 & 3 \\
5 & Description of pain & 0 & 1 \\
6 & Restlessness & 0 & 1 \\
7 & Excruciating agony & 0 & 1 \\
8 & Headache at specific times & 0 & 1 \\
9 & Strictly unilateral pain & 0 & 1 \\
10 & Ipsilateral cranial autonomic symptoms & 0 & 1 \\
11 & Treated attack duration $\leq 3 \mathrm{~h}$ & 0 & 1 \\
12 & Untreated attack duration $\leq 3 \mathrm{~h}$ & 0 & 1 \\
Total Score & & 3 & 32 \\
\hline
\end{tabular}




\subsection{Sensitivity and Specificity and the Receiver Operating Characteristics (ROC)}

Specificity, sensitivity, false positive rate, false negative rate, positive and negative predictive values, and positive and negative likelihood ratios were calculated for the items with dichotomous responses [35]. Descriptive statistics (mean and 95\% confidence intervals) and ROC curve statistics were computed to determine how the total scores could be interpreted to distinguish between patients diagnosed with $\mathrm{CH}$ versus migraine [36]. The ROC curve also permitted the identification of a cut-off test score that best distinguished between patients with $\mathrm{CH}$ and migraine. This cut-off test score was indicated by the inflection point on the ROC curve that was closest to the top left corner [37]. We also performed gender segregated analysis as follows: we separated the data set into male and females. For females, we performed class balancing to equalise the number of occurrences of $\mathrm{CH}$ and migraine. For males, we did not perform balancing as the data set is approximately balanced. A total sample size of about 300 subjects is generally required to provide accurate estimates for sensitivity and specificity for most screening or diagnostic tests involving two groups of patients, among which a specified disease is either present or absent [38]. The analysis was performed using the software $\mathrm{R}$ version 3.5.1.

\section{Results}

\subsection{Description of the Sample}

The sample consisted of 296 patients, which were classified into the following two groups: the case group and the control group. The case group consisted of patients diagnosed with $\mathrm{CH}(n=81,27.4 \%)$, of whom 45 patients were diagnosed with chronic $\mathrm{CH}(55.6 \%)$ and 36 with episodic $\mathrm{CH}(44.4 \%)$. The control group consisted of patients with migraine $(n=215,72.6 \%)$, of whom 123 were patients with chronic migraine (57.2\%) and 92 patients with episodic migraine $(42.8 \%)$. The ages of the patients ranged from 18 to 79 years (mean $=43.8 ; 95 \% \mathrm{CI}=42.3,45.6)$. Patients with $\mathrm{CH}$ had a mean age of $46.06(95 \% \mathrm{CI}=43.18,44.94)$ and patients with migraine had a mean age of $42.93(95 \% \mathrm{CI}=41.02$; 44.83). The $\mathrm{CH}$ group was comprised of 51 males and 30 females (male:female ratio: 1:7) whilst the migraine group consisted of 35 males and 180 females (female:male ratio: 5:14). The females had a mean age of $42.8(95 \%$ CI $41 ; 44.7)$ whilst males had a mean age of $46(95 \%$ CI $42.9 ; 49.1)$.

\subsection{Descriptive Analysis of Test Scores}

Table 3 summarizes the frequency distributions of the test scores classified by diagnosis. The image preference with the highest frequency was image ' $\mathrm{d}$ ' for $\mathrm{CH}(61.9 \%)$; whereas image ' $b$ ' (21.5\%) and image ' $c$ ' (23.3\%) were the highest frequencies for migraine. Image ' $d$ ' was rated as showing excruciating pain by most healthy participants in a study by our research team, while image ' $c$ ' was rated as moderate/severe and image ' $b$ ' as severe [22].

Table 3. Frequency distribution of the test scores classified by diagnosis.

\begin{tabular}{llccc}
\hline \multirow{3}{*}{ Test Item } & & \multicolumn{2}{c}{ \% within Diagnosis } \\
\cline { 3 - 4 } & & Category & Case Group & Control Group \\
\cline { 3 - 4 } & & $\begin{array}{c}\text { CH } \\
(n=81)\end{array}$ & $\begin{array}{c}\text { Migraine } \\
(\boldsymbol{n}=\mathbf{2 1 5})\end{array}$ \\
\hline \multirow{3}{*}{ Image preference } & $\mathrm{a}$ & 4.7 & 18.9 \\
\hline & $\mathrm{b}$ & 10.8 & 21.5 \\
\hline & $\mathrm{c}$ & 3.9 & 23.3 \\
\hline & $\mathrm{d}$ & $\mathbf{6 1 . 9}$ & $\mathbf{1 8 . 0}$ \\
\hline & $\mathrm{e}$ & 8.3 & 7.4 \\
\hline & $\mathrm{f}$ & 10.3 & 14.3 \\
\hline
\end{tabular}


Table 3. Cont.

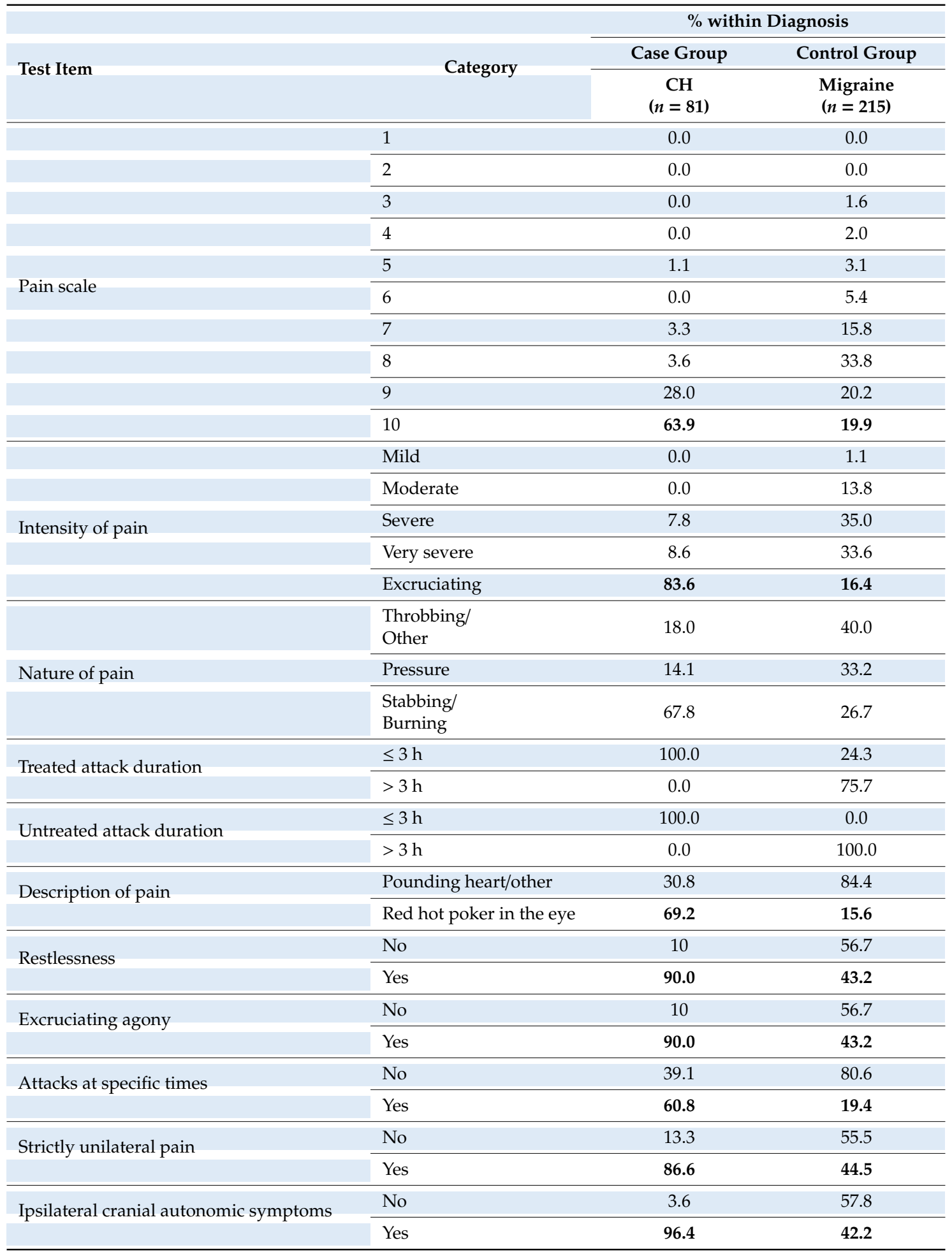

Key findings are highlighted in bold.

The description of pain with the highest frequency was 'red hot poker in the eye' for patients diagnosed with $\mathrm{CH}(69.2 \%)$, whereas 'pounding heart in head/other' was the highest frequency for patients diagnosed with migraine (84.4\%). Most patients diagnosed with $\mathrm{CH}(90 \%)$ reported the presence of restlessness during the attacks, compared to less than half of the patients with migraine (43.2\%). 
Most patients diagnosed with $\mathrm{CH}(96.4 \%)$ reported the presence of 'ipsilateral cranial autonomic symptoms', whereas most patients diagnosed with migraine (57.8\%) reported the absence of 'ipsilateral cranial autonomic symptoms'.

\subsection{Sensitivity and Specificity of the Test Scores}

Table 4 shows the sensitivity and specificity statistics for the eight test items that used dichotomous responses.

The presence of 'ipsilateral cranial autonomic symptoms' had a high sensitivity (96\%) but a moderate false positive rate (43\%). 'Excruciating agony' also had a high sensitivity (93\%) but a higher false positive rate (67\%). 'Restlessness' was a symptom with high sensitivity (90\%) and a moderate false positive rate $(44 \%)$. 'Strictly unilateral attacks' had a high specificity $(86 \%)$ and a moderate false positive rate $(44 \%)$. The 'Description of pain' had a lower level of sensitivity $(68 \%)$ than the other symptoms, but it also had a lower false positive rate (16\%). 'Headaches at specific times' had a low sensitivity $(60 \%)$ but also with a low false positive rate $(19 \%)$.

\subsection{ROC Analysis for Whole Data Set}

Figure 2 illustrates the ROC curves for 'Image preference', 'Pain scale', 'Intensity of pain', 'Nature of pain', and 'Total score'. The areas under all of the ROC curves were $>0.5(p<0.001)$, implying that the specified variables significantly distinguished between patients with $\mathrm{CH}$ and patients with migraine. None of the tests were worthless. The ROC curves also permitted the identification of cut-off test scores that best distinguished between patients with $\mathrm{CH}$ and patients with migraine. The cut-off scores are identified in Table 5. Based on the area under the curve (AUC), the most accurate test was 'Total score' $(0.955=$ good); followed in order of magnitude by 'Intensity of pain' $(0.841=$ good); 'Pain scale' $(0.799$ = fair); 'Image preference' $(0.723=$ fair $)$; and 'Nature of pain' ( $0.702=$ fair). The 'Total score' for the 12 items appeared to provide a more accurate method to distinguish between patients with $\mathrm{CH}$ and patients with migraine than the separate scores for 'Image Preference', 'Pain scale', 'Intensity of pain', and 'Nature of pain'. When the images are removed, the 'Total score' is a more accurate test (sensitivity $92.6 \%$, specificity $93.9 \%$ ) than the 'Total score' of the 12 items (sensitivity $86.4 \%$, specificity 92.0\%). Patients with $\mathrm{CH}$ had a higher mean score $(28.4 ; 95 \%$ CI $27.7 ; 29,1)$ compared to patients with migraine $(19.5 ; 95 \%$ CI 19; 20).

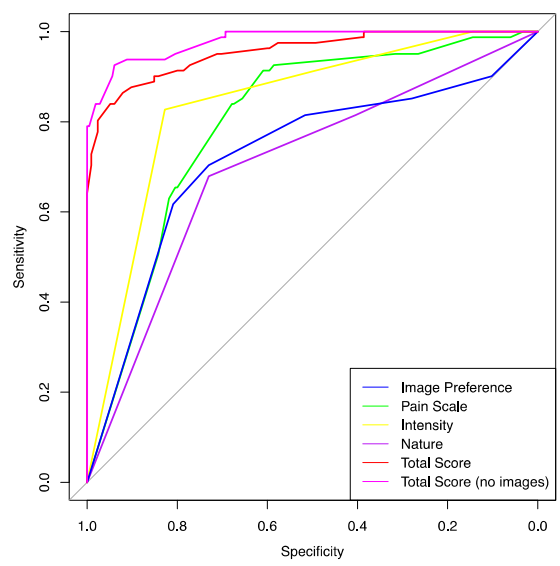

Figure 2. Receiver Operating Characteristics (ROC) curves for whole data set. The area under the curve $($ AUC) Total score $=0.955$; Total score $($ no images $)=0.979 ;$ AUC Intensity $=0.841$; AUC Pain scale $=0.799$; AUC Image preference $=0.723$; AUC Nature of pain $=0.702 ;$ AUC; area under the ROC curve is significantly greater than $0.5(p<0.001)$. 
Table 4. Sensitivity and specificity statistics for items with dichotomous responses.

\begin{tabular}{llllll}
\hline Test item & $\begin{array}{l}\text { Sensitivity\% } \\
\text { (CI) }\end{array}$ & $\begin{array}{l}\text { Specificity\% } \\
\text { (CI) }\end{array}$ & $\begin{array}{l}\text { PPV\% } \\
\text { (CI) }\end{array}$ & $\begin{array}{l}\text { NPV\% } \\
\text { (CI) }\end{array}$ & $\begin{array}{l}\text { FPR\% } \\
\text { (CI) }\end{array}$ \\
\hline Description of pain & $68(58 ; 78)$ & $84(79 ; 89)$ & $62(52 ; 72)$ & $87(83 ; 92)$ & $16(11 ; 21)$ \\
\hline Presence of restlessness & $90(84 ; 97)$ & $56(50 ; 63)$ & $44(36 ; 51)$ & $94(90 ; 98)$ & $44(37 ; 50)$ \\
\hline Excruciating agony & $93(87 ; 98)$ & $33(27 ; 40)$ & $34(28 ; 41)$ & $92(86 ; 98)$ & $67(60 ; 73)$ \\
\hline Attacks at specific times & $60(50 ; 71)$ & $81(76 ; 86)$ & $54(44 ; 65)$ & $84(80 ; 89)$ & $19(14 ; 24)$ \\
\hline Strictly unilateral pain & $86(79 ; 94)$ & $56(49 ; 62)$ & $42(35 ; 50)$ & $92(87 ; 96)$ & $44(38 ; 51)$ \\
\hline Ipsilateral cranial autonomic symptoms & $96(92 ; 100)$ & $57(50 ; 63)$ & $46(38 ; 53)$ & $98(95 ; 100)$ & $43(37 ; 50)$ \\
\hline Treated attack duration $\leq 3 \mathrm{~h}$ & $100(100 ; 100)$ & $77(71 ; 82)$ & $62(54 ; 70)$ & $100(100 ; 100)$ & $23(18 ; 29)$ \\
\hline Untreated attack duration $\leq 3 \mathrm{~h}$ & $100(100 ; 100)$ & $100(100 ; 100)$ & $100(100 ; 100)$ & $100(100 ; 100)$ & $0(0.0 ; 0.0)$ \\
\hline
\end{tabular}

PPV: positive predictive value; NPV: negative predictive value; FPR: false positive rate; FNR: false negative rate; CI: $95 \%$ confidence interval. 
Table 5. Cut-off points on the ROC curves for whole data set.

\begin{tabular}{llll}
\hline Test Item & Cut-off & Sensitivity (\%) & Specificity (\%) \\
\hline Nature of pain & 3 (Stabbing/Burning) & 67.9 & 73.0 \\
\hline Image preference & 5 (Image 'e') & 70.3 & 73.0 \\
\hline Intensity of pain & 5 (Excruciating) & 82.7 & 82.7 \\
\hline Pain scale & 9 (out of 10) & 83.9 & 67.9 \\
\hline Total score & $\mathbf{2 5}$ (out of 32) & $\mathbf{8 6 . 4}$ & $\mathbf{9 2 . 0}$ \\
\hline Total score (no images) & $\mathbf{2 0 . 5}$ (out of 32) & $\mathbf{9 2 . 6}$ & $\mathbf{9 3 . 9}$ \\
\hline
\end{tabular}

\subsection{ROC Analysis According to Gender}

Figure 3 shows the ROC curves according to gender. The cut-off points on the ROC curves are presented in Table 6. Similar to the analysis including the whole data set, the 'Total score' is the most precise test in differentiating $\mathrm{CH}$ from migraine. The 'Total score' $>23$ (out of 32) has a high performance (sensitivity $90.1 \%$, specificity $94.2 \%$ ) in detecting males with $\mathrm{CH}$. The 'Total score' $>25 / 32$ has a lower sensitivity in detecting females with $\mathrm{CH}$ (sensitivity $90.0 \%$, specificity $91.6 \%$ ). Without the images, the 'Total score' has a slightly better performance than the 'Total score' of the 12-items for both male and female groups. The intensity of pain 'excruciating' has a higher specificity in detecting males with $\mathrm{CH}(91.4 \%)$ than females $(81.1 \%)$. The image preference has a higher performance in detecting females (sensitivity $73.3 \%$, specificity $79.4 \%$ ) than males with $\mathrm{CH}$ (sensitivity $66.6 \%$, specificity $77.1 \%$ ).

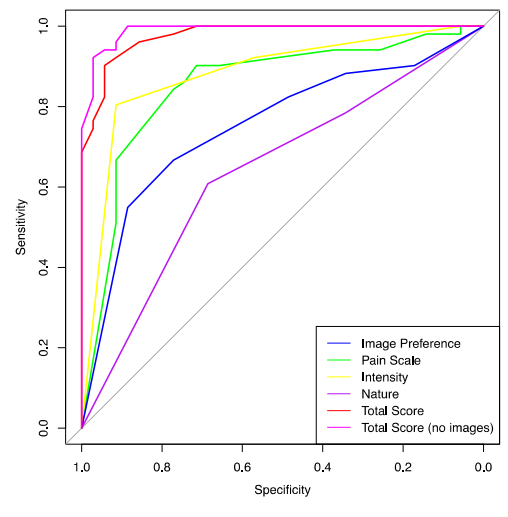

(a) ROC curve for the male group

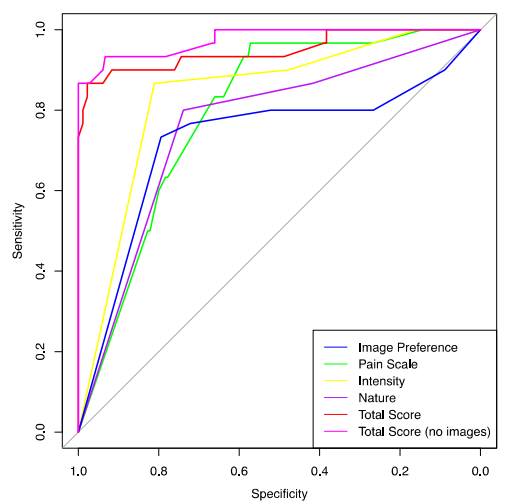

(b) ROC curve for the female group

Figure 3. ROC curves according to gender. The AUC male group: AUC Total score $=0.977$; AUC Total score $($ no images $)=0.979$; AUC Intensity $=0.881$; AUC Pain scale $=0.852$; AUC Image preference $=$ 0.751 ; AUC Nature of pain $=0.640$.

Table 6. ROC cut-off points for the male and female groups.

\begin{tabular}{llllllll}
\hline Statistics According to Gender & Nature of Pain & $\begin{array}{l}\text { Image } \\
\text { Preference }\end{array}$ & Intensity of Pain & Pain Scale & Total Score & $\begin{array}{l}\text { Total Score } \\
\text { (without Images) }\end{array}$ \\
\hline \multirow{2}{*}{ Cut off } & Male & 3 & 5 & 5 & 9 & $23.6 / 32$ & $20 / 32$ \\
\cline { 2 - 8 } & Female & 3 & 6 & 5 & 9 & $25.0 / 32$ & $20.5 / 32$ \\
\hline $\begin{array}{l}\text { Sensitivity } \\
(\%)\end{array}$ & Male & 60.7 & 66.6 & 80.3 & 84.3 & 90.1 & 94.1 \\
\hline $\begin{array}{l}\text { Specificity } \\
(\%)\end{array}$ & Female & 80.0 & 73.3 & 86.6 & 83.3 & 90.0 & 93.3 \\
\hline
\end{tabular}

Nature of pain $3=$ Stabbing/burning; Image preference $5=$ Image 'e'; Image preference = Image 'd'; Intensity of pain 5 = Excruciating; Pain scale 9 (out of 10). 
The AUC female group: AUC Total score = 0.948; AUC Total score (no images) = 0.975; AUC Intensity = 0.838; AUC Pain scale = 0.795; AUC Image preference $=0.726$; AUC Nature of pain $=0.761$. The area under the ROC curve is significantly greater than $0.5(p<0.001)$.

\subsection{ROC Analysis with Class Balancing}

To evaluate the influence of the unbalanced classes on the statistical analysis in Figures 2 and 3 we performed ROC analysis with class balancing. The data set is unbalanced in two ways: more females than males and more occurrences of migraines than $\mathrm{CH}$ are in the data set. Figure 4 shows the mean ROC curve and associated 95\% CI of the 'Total score' for the whole data set and for the female group, respectively, after class balancing. Balancing was performed by gathering 10 random under-samplings of the occurrences of migraine from the complete data set, including both males and females. The ROC curve for each realization of the random under-sampling were averaged to obtain the presented ROC curves. Class balancing does not alter the characteristics of the ROC curve.

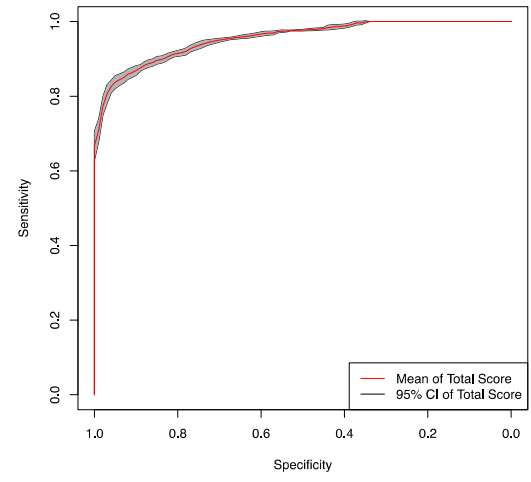

(a) Whole data set

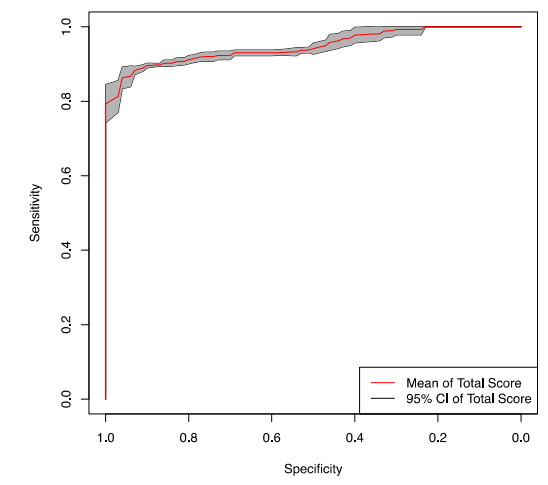

(b) Female group

Figure 4. ROC curve of the 'Total score' after class balancing.

\section{Discussion}

In this study, we developed a self-administered screening questionnaire for $\mathrm{CH}$. The main objectives of this study were to determine the overall performance of the questionnaire and the performance of the test items that best discriminate between $\mathrm{CH}$ and migraine. The results were interpreted assuming that a screening test should ideally exhibit a high level of sensitivity (to detect as many true positives as possible).

\subsection{Clinical Indicators of $\mathrm{CH}$ versus Migraine}

Current research indicates that the key differences between $\mathrm{CH}$ and migraine are the severity of pain, restlessness behaviour during attacks [3], and prominent ipsilateral cranial autonomic symptoms [39]. $\mathrm{CH}$ is often described in the literature as the 'most severe pain known to man' [28,40-42]. Such a pain descriptor is not usually attributed to migraines [43]. The attacks described like an 'excruciating agony' in our study proved to have a low specificity (33\%). Although 'excruciating agony' had a high sensitivity (93\%) in detecting $\mathrm{CH}$, almost half of the patients with migraine $(43 \%)$ chose this descriptor of pain. Therefore, the descriptor 'excruciating' might not apply only to $\mathrm{CH}$ patients [40] but also describes the severity of migraine attacks, as shown by our study. The descriptor of pain 'excruciating agony' is not a good discriminator between $\mathrm{CH}$ and migraine, according to our questionnaire study. When patients had to choose the intensity of pain from mild to excruciating, this descriptor of pain was a more accurate test (sensitivity $82.7 \%$, specificity $82.7 \%$ ). This highlights the importance of question phrasing that could influence the pain information provided [44]. Furthermore, pain reporting is subjected to multiple biases. In a stressful situation, recall of pain intensity is exaggerated and also chronic pain is itself associated with an overestimation of pain intensity [45]. Additionally, associated 
psychiatric co-morbidities could have an influence on how pain is reported [46]. The self-report of physical pain can be subjected to recollection bias [45,47]. Patients with $\mathrm{CH}$ overestimated the severity of retrospective attacks compared to the attacks recorded prospectively [48].

It is known from the literature that $\mathrm{CH}$ has very characteristic clinical features: restlessness during attacks and ipsilateral autonomic cranial symptoms [3]. These clinical characteristics had a high sensitivity $(>90 \%)$ but with low specificity $(<60 \%)$ which meant they were present in nearly all patients with $\mathrm{CH}$ and also present in many patients with migraine. Previous studies report variable results for the presence of restlessness during $\mathrm{CH}$ attacks (80\% [49], 67.9\% [10], 51\% [50]). This could be due to differences in question phrasing even though the questionnaires used for data collection were not published $[10,49,50]$. According to previous reports, the presence of restlessness had a higher sensitivity in patients with chronic $\mathrm{CH}$ (sensitivity $100 \%$, specificity $90 \%$ ) than episodic $\mathrm{CH}$ (sensitivity $82 \%$, specificity $92 \%$ ) [51]. Although the cranial autonomic symptoms have been reported in $56 \%$ of patients with migraine, they are less severe, usually bilateral and inconsistent from one attack to the other [39]. In contrast, the cranial autonomic symptoms reported in $94 \%$ of patients with $\mathrm{CH}$ are severe, unilateral, and consistently present from one attack to the other [39]. In our study, the presence of ipsilateral cranial autonomic symptoms were reported in $96.4 \%$ of patients with $\mathrm{CH}$ and $42.2 \%$ of patients with migraine, similar to previous reports [39].

More research is required to identify the descriptors of pain that best differentiate between $\mathrm{CH}$ and migraine. Untreated attack duration $(3 \mathrm{~h})$ was the test item with the highest sensitivity $(100 \%)$ and specificity (100\%). Previous reports showed similar findings [51-53]. According to previous studies, the untreated attack duration of $\leq 3 \mathrm{~h}$ is one of the best clinical features to discriminate between $\mathrm{CH}$ and other primary headaches [51-53]. However, this is the result of strictly applying the ICHD-3b criteria [3], where $\mathrm{CH}$ patients with attacks longer than $3 \mathrm{~h}$ are excluded from the research studies. This study showed many overlapping features between $\mathrm{CH}$ and migraine which could account for diagnostic delays and misdiagnosis. There is no single test item that can differentiate between the two conditions. However, the total screening tool score with a cut-off $>25 / 32$ was highly sensitive $(86.4 \%)$ and specific $(92.0 \%)$ in differentiating $\mathrm{CH}$ from migraine. This tool is designed as a screening instrument, and further confirmation of diagnosis from a specialist is required.

\subsection{Screening Tools for $\mathrm{CH}$}

Multiple proposals have been made for screening and diagnostic tools for $\mathrm{CH}$ [34,52]. A screening tool with 8 -items was found to have a high sensitivity $(95 \%)$ and specificity $(96 \%)$ in detecting $\mathrm{CH}$ [34]. This study, which included 42 patients with $\mathrm{CH}$, of whom one patient had chronic $\mathrm{CH}$, should be repeated in a higher population of patients with chronic $\mathrm{CH}$ to avoid selection bias [34]. A lengthy 142-item web based questionnaire was tested in a large population of 437 patients with self-reported $\mathrm{CH}$ [52]. Three questions were identified to predict $\mathrm{CH}$ : untreated attack duration of 15 to $180 \mathrm{~min}$, an attack free period of four months to three years, and the male gender (sensitivity $53.8 \%$, specificity $88.9 \%$, positive predictive value $95.5 \%$, and negative predictive value $30.8 \%$ [52]). The three-item questionnaire was not independently tested and the study did not include a control group [52]. Fritsche et al. tested a 20-item German language questionnaire to diagnose migraine, tension type headache, and trigeminal autonomic cephalalgias (TACs) in a tertiary headache centre [54]. The exact types of TACs are not specified and therefore the number of diagnosed $\mathrm{CH}$ cases is unknown [54]. The same questionnaire developed by Fritsche et al. was tested in a general population with headache by Yoon et al. [55] and Kukava et al. [56]. An analysis algorythm based on the ICHD criteria was used to diagnose different types of headaches, but the algorythm details were not provided [54]. The questionnaire proved to be more useful at detecting a migraine and tension type headache and it overdiagnosed patients with $\mathrm{CH}$ [54]. 


\subsection{Images Depicting Headache Pain}

Pain experience involves a complex relationship between sensory and emotional factors [57]. The diagnosis process is usually focused on the sensory experience of pain while the emotional factors are neglected [58]. Images depicting headache pain are a more complex representation of the pain experience as they also capture the affective aspect of pain [59]. This study showed that images with a higher intensity (image ' $\mathrm{e}$ ' and image ' $\mathrm{d}$ ') could differentiate between $\mathrm{CH}$ and migraine but the performance was moderate (sensitivity $70.3 \%$, specificity $73 \%$ ). Images are more precise in detecting females than males with $\mathrm{CH}$. This could be due to several biases related to pain reporting as mentioned above $[45,46]$. Overall, the images depicting headache pain have a low influence in detecting a cluster headache. Although the intensity of pain captured via visual analogue scale and the intensity from mild to excruciating are more accurate tests than the images in detecting headache severity, they have a moderate specificity in detecting $\mathrm{CH}$. This could imply that the intensity of pain is not a good differentiator between the two conditions. Other images with different artistic characteristics might have a higher performance in distinguishing between $\mathrm{CH}$ and migraine. Additionally, future research should capture the emotional responses evoked by images depicting headache pain in order to better understand their role in the diagnosis of primary headaches. This study is the first step in the development and validation of a screening tool for $\mathrm{CH}$. As this tool was tested in a headache centre on patients who already received a diagnosis, it requires evaluation in other clinical settings, including primary care, before a diagnosis is made. A shorter screening tool should be validated, including items that best differentiated between $\mathrm{CH}$ and migraine according to this study.

\subsection{Strengths and Limitations}

The strength of our study consists in a large sample size and the inclusion of a control group of migraine patients, the most common misdiagnosis of $\mathrm{CH}$ [38]. This study opens a new field of research as it is the first study of its kind to test the usefulness of images depicting headache pain in the detection of $\mathrm{CH}$, although the images in this study do not clearly differentiate between $\mathrm{CH}$ and migraine. The present study was subjected to limitations. The patients were recruited from a headache centre after they received a diagnosis of $\mathrm{CH}$ or migraine, which may have resulted in a selection bias of the enrolled patients. This study lays the foundation for the validation of the screening tool, which requires further evaluation in population-based studies. A single centre study is another limitation and it should be reproduced in other clinical settings. This study may have been subjected to recall bias, a limitation of all questionnaire studies. Our study was based on the ICHD-3b criteria, which included the recently deleted symptoms (fullness in the ear, facial and forehead flushing) from the ICHD-3 criteria and extending the maximum remission periods of chronic $\mathrm{CH}$ to up to three months. Although there was no difference in reporting ipsilateral ear fullness and facial flushing between patients who received a diagnosis of $\mathrm{CH}$ and patients who did not [60], the screening tool needs to be evaluated with the current ICHD-3 criteria.

\section{Conclusions}

This is the first study of its kind to develop a screening tool with images depicting headache pain to aid the diagnosis of $\mathrm{CH}$. The overall tool score could be a good instrument in the screening of $\mathrm{CH}$. Images depicting headache pain do not clearly discriminate between $\mathrm{CH}$ and migraine. Our study also provides valuable insight into what problems clinicians may be facing in real life to explain the delay in diagnosis.

Supplementary Materials: The following are available online at http://www.mdpi.com/2076-3425/10/2/77/s1, File: The screening tool for $\mathrm{CH}$

Author Contributions: A.B. and F.A. conceptualised and designed the study. A.B. collected, analysed and interpreted the data. A.B. drafted the manuscript, with input from F.A., J.W.B. and L.D. C.H. supported A.B. 
with the statistical methodology and reviewed the statistical analysis. All authors have read and agreed to the published version of the manuscript

Funding: The data used in this article were collected as part of a doctoral research project carried out at Hull York Medical School, funded by a Research Fellowship from the Headache Research Funds at Hull University Teaching Hospitals NHS Trust, UK.

Acknowledgments: We would like to thank Aziz Asghar for his critical comments throughout the course of AB's doctoral project. The research team was inspired by Migraine Action and ARTe Cluster Project and it was precisely their artistic and creative contributions to raising awareness of $\mathrm{CH}$ that led us to explore the potential of using images in screening for primary headaches. We thank all the study participants.

Conflicts of Interest: F.A. served as an advisory board member and received honoraria from Allergan, Novartis, TEVA, Electrocore and Eneura, which he donated to charitable organisations (Migraine Trust, BASH and ADMA). The other authors report no conflicts of interest in this work.

Availability of Data and Material: The datasets used and/or analysed during this study are available from the corresponding author upon request.

\section{References}

1. Goadsby, P.J.; Wei, D.Y.-T.; Ong, J.J.Y. Cluster headache: Epidemiology, pathophysiology, clinical features, and diagnosis. Ann. Indian Acad. Neurol. 2018, 21, S3-S8. [CrossRef]

2. Choong, C.K.; Ford, J.H.; Nyhuis, A.W.; Robinson, R.L.; Aurora, S.K. Health Care Utilization and Direct Costs Among Patients Diagnosed with Cluster Headache in U.S. Health Care Claims Data. J. Manag. Care Spéc. Pharm. 2018, 24, 921-928. [CrossRef] [PubMed]

3. Headache Classification Committee of the International Headache Society (IHS) The International Classification of Headache Disorders, 3rd edition. Cephalalgia 2018, 38, 1-211. [CrossRef] [PubMed]

4. Lund, N.; Barloese, M.; Petersen, A.; Haddock, B.; Jensen, R. Chronobiology differs between men and women with cluster headache, clinical phenotype does not. Neurology 2017, 88, 1069-1076. [CrossRef] [PubMed]

5. Vikelis, M.; Rapoport, A.M. Cluster headache in Greece: an observational clinical and demographic study of 302 patients. J. Headache Pain 2016, 17, 88. [CrossRef] [PubMed]

6. Del Rio, M.S.; Leira, R.; Pozo-Rosich, P.; Laínez, J.M.; Alvarez, R.; Pascual, J. Errors in Recognition and Management are Still Frequent in Patients with Cluster Headache. Eur. Neurol. 2014, 72, 209-212. [CrossRef] [PubMed]

7. Rozen, T.D.; Fishman, R.S. Cluster headache in the United States of America: demographics, clinical characteristics, triggers, suicidality, and personal burden. Headache 2012, 52, 99-113. [CrossRef]

8. Van Alboom, E.; Louis, P.; Van Zandijcke, M.; Crevits, L.; Vakaet, A.; Paemeleire, K. Diagnostic and therapeutic trajectory of cluster headache patients in Flanders. Acta Neurol. Belg. 2009, 109, 10-17.

9. Voiticovschi-Iosob, C.; Allena, M.; De Cillis, I.; Nappi, G.; Sjaastad, O.; Antonaci, F. Diagnostic and therapeutic errors in cluster headache: A hospital-based study. J. Headache Pain 2014, 15, 56. [CrossRef]

10. Schürks, M.; Kurth, T.; De Jesus, J.; Jonjic, M.; Rosskopf, D.; Diener, H.-C. Cluster Headache: Clinical Presentation, Lifestyle Features, and Medical Treatment. Headache: J. Head Face Pain 2006, 46, 1246-1254. [CrossRef]

11. Joshi, S.; Rizzoli, P.; Loder, E. The comorbidity burden of patients with cluster headache: A population-based study. J. Headache Pain 2017, 18, 76. [CrossRef] [PubMed]

12. Gooriah, R.; Buture, A.; Ahmed, F. Evidence-based treatments for cluster headache. Ther. Clin. Risk Manag. 2015, 11, 1687-1696. [CrossRef] [PubMed]

13. Buture, A.; Ahmed, F.; Dikomitis, L.; Boland, J.W. Systematic literature review on the delays in the diagnosis and misdiagnosis of cluster headache. Neurol. Sci. 2018, 40, 25-39. [CrossRef] [PubMed]

14. Jensen, R.; Lyngberg, A.; Jensen, R. Burden of Cluster Headache. Cephalalgia 2007, 27, 535-541. [CrossRef]

15. Choi, Y.-J.; Kim, B.-K.; Chung, P.-W.; Lee, M.J.; Park, J.-W.; Chu, M.K.; Ahn, J.-Y.; Kim, B.-S.; Song, T.-J.; Sohn, J.-H.; et al. Impact of cluster headache on employment status and job burden: A prospective cross-sectional multicenter study. J. Headache Pain 2018, 19, 78. [CrossRef]

16. Bahra, A.; Goadsby, P.J. Diagnostic delays and mis-management in cluster headache. Acta Neurol. Scand. 2004, 109, 175-179. [CrossRef]

17. Buture, A.; Boland, J.W.; Dikomitis, L.; Ahmed, F. Update on the pathophysiology of cluster headache: Imaging and neuropeptide studies. J. Pain Res. 2019, 12, 269-281. [CrossRef] 
18. Ferraro, S.; Nigri, A.; Bruzzone, M.G.; Demichelis, G.; Pinardi, C.; Brivio, L.; Giani, L.; Proietti, A.; Leone, M.; Chiapparini, L. Cluster headache: Insights from resting-state functional magnetic resonance imaging. Neurol. Sci. 2019, 40, 45-47. [CrossRef]

19. Gibson, K.F.; Santos, A.D.; Lund, N.; Jensen, R.; Stylianou, I.M. Genetics of cluster headache. Cephalalgia 2019, 39, 1298-1312. [CrossRef]

20. Morris, J.; Straube, A.; Diener, H.-C.; Ahmed, F.; Silver, N.; Walker, S.; Liebler, E.; Gaul, C. Cost-effectiveness analysis of non-invasive vagus nerve stimulation for the treatment of chronic cluster headache. J. Headache Pain 2016, 17, 43. [CrossRef]

21. Martelletti, P.; Jensen, R.H.; Antal, A.; Arcioni, R.; Brighina, F.; De Tommaso, M.; Franzini, A.; Fontaine, D.; Heiland, M.; Jürgens, T.P.; et al. Neuromodulation of chronic headaches: position statement from the European Headache Federation. J. Headache Pain 2013, 14, 86. [CrossRef] [PubMed]

22. Buture, A.; Boland, J.W.; Ahmed, F.; Dikomitis, L. Images depicting headache pain-A tool to aid the diagnosis of cluster headache: A pilot study. J. Multidiscip. Heal. 2019, 12, 691-698. [CrossRef] [PubMed]

23. ICHD3beta. The international classification of headache disorders: 3rd edition (beta version). Cephalalgia 2013, 33, 629-808. [CrossRef]

24. Alcecluster. Available online: http://alcecluster.cefalea.it/ (accessed on 27 February 2019).

25. Rossi, P.; Geraci, C.; Navarro, F.M. EHMTI-0041. ARTe Cluster project. Cluster headache-From pain to inspiration. J. Headache Pain 2014, 15, C55. [CrossRef]

26. Migraine Art Collection. Available online: http://www.migraineart.org.uk (accessed on 16 June 2019).

27. Art by Faderhead. Available online: https://www.deviantart.com/faderhead/art/Migraine-Headache-286959 (accessed on 16 June 2019).

28. Ahmed, F.; Dikomitis, L.; Zafar, H.; Goadsby, P.; Paemeliere, K. EHMTI-0357. Perceptions and experiences of cluster headache among patients, general practitioners and neurologists in the north of england: A qualitative study. J. Headache Pain 2014, 15, J1. [CrossRef]

29. Khoo, S.B. Masqurades of Cluster headache. Malays Fam Physician. 2009, 4, 51-56. [PubMed]

30. Tsang, S.; Royse, C.F.; Terkawi, A.S. Guidelines for developing, translating, and validating a questionnaire in perioperative and pain medicine. Saudi J. Anaesth. 2017, 11, 80-S89. [CrossRef]

31. Van Der Meer, H.A.; Visscher, C.M.; Engelbert, R.H.; Mulleners, W.M.; Van Der Sanden, M.W.N.; Speksnijder, C.M. Development and psychometric validation of the headache screening questionnaire-Dutch Version. Musculoskelet. Sci. Pr. 2017, 31, 52-61. [CrossRef]

32. Trochim, W.M.K. “Descriptive statistics” Research Methods Knowledge Base. Retrieved October 2006, 10, 2011.

33. Mehta, N.; Maloney, G.E.; Bana, D.S.; Scrivani, S.J. Head, Face, and NeckPain Science, Evaluation, and Management: An Interdisciplinary Approach; John Wiley \& Sons: Hoboken, NJ, USA, 2011.

34. Chung, P.W.; Cho, S.J.; Kim, B.K.; Kim, S.K.; Lee, M.J.; Choi, Y.J.; Park, J.W.; Kim, B.S.; Oh, K.; Moon, H.S.; et al. Development and Validation of the Cluster Headache Screening Questionnaire. J. Clin. Neurol. 2019, 15, 90-96. [CrossRef]

35. Trevethan, R. Sensitivity, Specificity, and Predictive Values: Foundations, Pliabilities, and Pitfalls in Research and Practice. Front. Public Health 2017, 5, 307. [CrossRef] [PubMed]

36. Tape, G.T. Interpreting Diagnostic Tests. Introduction to ROC curves. Available online: http://gim.unmc.edu/ dxtests/ROC1.htm (accessed on 10 May 2019).

37. Unal, I. Defining an Optimal Cut-Point Value in ROC Analysis: An Alternative Approach. Comput. Math. Methods Med. 2017, 2017, 1-14. [CrossRef] [PubMed]

38. Bujang, M.A.; Adnan, T.H. Requirements for Minimum Sample Size for Sensitivity and Specificity Analysis. J. Clin. Diagn. Res. 2016, 10, YE01-YE06. [CrossRef] [PubMed]

39. Lai, T.H.; Fuh, J.L.; Wang, S.J. Cranial autonomic symptoms in migraine: Characteristics and comparison with cluster headache. J. Neurol. Neurosurg. Psychiatry 2009, 80, 1116-1119. [CrossRef] [PubMed]

40. May, A.; Schwedt, T.J.; Magis, D.; Pozo-Rosich, P.; Evers, S.; Wang, S.J. Cluster headache. Nat. Rev. Dis. Primers. 2018, 4, 18006. [CrossRef] [PubMed]

41. Ekbom, K.; Hardebo, J.E. Cluster headache: aetiology, diagnosis and management. Drugs 2002, 62, 61-69. [CrossRef]

42. Magis, D. Emerging treatments for cluster headache: hopes and disappointments. Curr. Opin. Neurol. 2019, 32, 432-437. [CrossRef] 
43. Vollesen, A.L.; Benemei, S.; Cortese, F.; Labastida-Ramírez, A.; Marchese, F.; Pellesi, L.; Romoli, M.; Ashina, M.; Lampl, C.; School of Advanced Studies of the European Headache Federation (EHF-SAS); et al. Migraine and cluster headache-The common link. J. Headache Pain 2018, 19, 89. [CrossRef]

44. McDonald, D.D.; Shea, M.; Rose, L.; Fedo, J. The Effect of Pain Question Phrasing on Older Adult Pain Information. J. Pain Symptom Manag. 2010, 37, 1050-1060. [CrossRef]

45. Daoust, R.; Sirois, M.-J.; Lee, J.S.; Perry, J.J.; Griffith, L.E.; Worster, A.; Lang, E.; Paquet, J.; Chauny, J.-M.; Émond, M. Painful Memories: Reliability of Pain Intensity Recall at 3 Months in Senior Patients. Pain Res. Manag. 2017, 2017, 1-7. [CrossRef]

46. Garbi, M.D.O.S.S.; Hortense, P.; Gomez, R.R.F.; Silva, T.D.C.R.D.; Castanho, A.C.F.; Sousa, F.A.E.F. Pain intensity, disability and depression in individuals with chronic back pain1. Rev. Latino-Americana de Enferm. 2014, 22, 569-575. [CrossRef] [PubMed]

47. Karimi, Z.; Pilenko, A.; Held, S.M.; Hasenbring, M.I. Recall Bias in Patients with Chronic Low Back Pain: Individual Pain Response Patterns Are More Important Than Pain Itself! Int. J. Behav. Med. 2016, 23, 12-20. [CrossRef] [PubMed]

48. Snoer, A.H.; Lund, N.; Jensen, R.H.; Kristoffersen, E.S.; Barloese, M.; Hansen, J.M. More precise phenotyping of cluster headache using prospective attack reports. Eur. J. Neurol. 2019, 26, 1303-e85. [CrossRef]

49. Bhargava, A.; Pujar, G.S.; Banakar, B.F.; Kasundra, G.; Bhushan, B.; Shubhakaran, K. Study of cluster headache: A hospital-based study. J. Neurosci. Rural. Pr. 2014, 5, 369-373. [CrossRef] [PubMed]

50. Lin, K.-H.; Wang, P.-J.; Fuh, J.-L.; Lu, S.-R.; Chung, C.-T.; Tsou, H.-K.; Wang, S.-J. Cluster Headache in the Taiwanese-A Clinic-Based Study. Cephalalgia 2004, 24, 631-638. [CrossRef] [PubMed]

51. Torelli, P.; Beghi, E.; Manzoni, G.C. Validation of a Questionnaire for the Detection of Cluster Headache. Headache: J. Head Face Pain 2005, 45, 644-652. [CrossRef]

52. A Wilbrink, L.; Weller, C.M.; Cheung, C.; Stijnen, T.; Haan, J.; Ferrari, M.D.; Terwindt, G.M. Stepwise web-based questionnaires for diagnosing cluster headache: LUCA and QATCH. Cephalalgia 2013, 33, 924-931. [CrossRef]

53. Dousset, V.; Laporte, A.; LeGoff, M.; Brochet, B.; Traineau, M.-H.; Dartigues, J.-F. Validation of a Brief Self-Administered Questionnaire for Cluster Headache Screening in a Tertiary Center. Headache: J. Head Face Pain 2009, 49, 64-70. [CrossRef]

54. Fritsche, G.; Hueppe, M.; Kukava, M.; Dzagnidze, A.; Schuerks, M.; Yoon, M.-S.; Diener, H.-C.; Katsarava, Z. Validation of a German Language Questionnaire for Screening for Migraine, Tension-Type Headache, and Trigeminal Autonomic Cephalgias. Headache: J. Head Face Pain 2007, 47, 546-551. [CrossRef]

55. Yoon, M.-S.; Obermann, M.; Fritsche, G.; Slomke, M.; Dommes, P.; Schilf, C.; Diener, H.-C.; Katsarava, Z. Population-Based Validation of a German-Language Self-Administered Headache Questionnaire. Cephalalgia 2008, 28, 605-608. [CrossRef]

56. Kukava, M.; Dzagnidze, A.; Mirvelashvili, E.; Djibuti, M.; Fritsche, G.; Jensen, R.; Stovner, L.J.; Steiner, T.J.; Katsarava, Z. Validation of a Georgian language headache questionnaire in a population-based sample. J. Headache Pain 2007, 8, 321-324. [CrossRef] [PubMed]

57. Peláez, I.; Ferrera, D.; Barjola, P.; Fernandes, R.; Mercado, F. Subliminal emotional pictures are capable of modulating early cerebral responses to pain in fibromyalgia. PLoS ONE 2019, 14, e0217909. [CrossRef] [PubMed]

58. Linton, S.J.; Shaw, W.S. Impact of Psychological Factors in the Experience of Pain. Phys. Ther. 2011, 91, 700-711. [CrossRef] [PubMed]

59. Schott, G.D. Pictures of pain: their contribution to the neuroscience of empathy. Brain 2015, 138, 812-820. [CrossRef] [PubMed]

60. De Coo, I.F.; Wilbrink, L.A.; Haan, J.; Ferrari, M.D.; Terwindt, G.M. Evaluation of the new ICHD-III beta cluster headache criteria. Cephalalgia 2016, 36, 547-551. [CrossRef]

(C) 2020 by the authors. Licensee MDPI, Basel, Switzerland. This article is an open access article distributed under the terms and conditions of the Creative Commons Attribution (CC BY) license (http://creativecommons.org/licenses/by/4.0/). 